\title{
Application of Polyvinyl Acetate/Lignin Copolymer as Bio-Based Coating Material and Its Effects on Paper Properties
}

\author{
Nana Zhang (D), Pansheng Liu, Yanbin Yi, Magdi E. Gibril *(D), Shoujuan Wang and Fangong Kong *D \\ Key Laboratory of Pulp \& Paper Science and Technology of Shandong Province/Ministry of Education, Qilu \\ University of Technology, Shandong Academy of Sciences, Jinan 250353, China; nanazhangabc@163.com (N.Z.); \\ 17862900069@163.com (P.L.); yyb_frighting@163.com (Y.Y.); wshj@qlu.edu.cn (S.W.) \\ * Correspondence: magdi.gibril@gmail.com (M.E.G.); kfgwsj1566@163.com (F.K.)
}

Citation: Zhang, N.; Liu, P.; Yi, Y.; Gibril, M.E.; Wang, S.; Kong, F. Application of Polyvinyl Acetate/Lignin Copolymer as Bio-based Coating Material and Its Effects on Paper Properties. Coatings 2021, 11, 192. https://doi.org/ 10.3390/coatings11020192

Academic Editors: Csaba Balázsi and Jean-François Berret

Received: 14 December 2020

Accepted: 5 February 2021

Published: 7 February 2021

Publisher's Note: MDPI stays neutral with regard to jurisdictional claims in published maps and institutional affiliations.

Copyright: (c) 2021 by the authors. Licensee MDPI, Basel, Switzerland. This article is an open access article distributed under the terms and conditions of the Creative Commons Attribution (CC BY) license (https:// creativecommons.org/licenses/by/ $4.0 /)$.

\begin{abstract}
In this work, lignin-vinyl acetate copolymers containing different fractions of lignin were synthesized by the copolymerization technique. The synthesized copolymer was successfully applied to coat the paper for enhancing its properties and performance. The effects of the lignin-vinyl acetate copolymer on the physicochemical, air permeability and mechanical properties of paper were investigated. The mechanical strength, hydrophilic, and air permeability properties of coated paper were improved with the increasing content of the lignin. Lignin-vinyl acetate copolymer containing $15 \%$ lignin coated paper exhibited a 1.86 times increase in the tensile index, 45 times increase in the water contact angle, and a $41.1 \%$ reduction in the air permeability compared with uncoated paper. Scanning electron microscopy was applied to study the morphology of the coated and uncoated paper. The results showed that paper surface porosity structure was decreased, while the surface smoothness was enhanced considerably with increasing lignin fraction in the copolymer. Therefore, the successful fabrication of such an enchanting coated paper may afford new potential and great applications in the packaging paper.
\end{abstract}

Keywords: lignin-vinyl acetate copolymer; coating paper; physicochemical and mechanical properties

\section{Introduction}

Paper is widely used in many industries and day-to-day life as a packaging material due to its unique properties such as flexibility, low cost, sustainability, recyclability, nontoxicity, and biodegradability [1]. However, poor water-resistance and low mechanical properties are the main reasons hindering its applications in wide fields [2]. This is the result of the complex chemical structure of cellulose fibers and their arrangement at different levels, namely at molecules, fibrils, fibers, and fiber mat (paper), which may have the main role in determining many end-uses and the properties of paper [3]. Therefore, there is an urgent demand for improving the physicochemical and mechanical properties.

Coating paper surface is a common technique to enhance the physicochemical and mechanical properties. Currently, different types of polymeric materials, including starch, polyvinyl alcohol (PVA), polyethylene (PE), silicone, and modified polyvinyl acetate (PVAc), have been used intensively in paper coating for enhancing its functional performance [2]. Amongst these polymeric materials, PVAc is a thermoplastic polymer obtained by polymerization of vinyl acetate monomers [4]. PVAc is non-toxic, inexpensive, easy to synthesize, and biodegradable. PVAc has being used widely in different daylife applications such as a raw material for the preparation of polyvinyl alcohol (PVA), adhesive glue for wood and paper, and as a thermosetting adhesive material [5-7]. Nevertheless, the low thermal stability of PVAc might hinder its potential practical applications as coating materials [7]. Consequently, there is considerable demand for enhancing the thermal stability of the PVAc using a facile method and inexpensive material to be more suitable and economical in paper coating [8]. Copolymerization of vinyl acetate (VAc) monomer with various petroleum-based monomers including ethylene, butyl acrylate (BA), vinyl chloride, and 
methyl methacrylate monomers has been applied as a common method to enhance some properties of the PVAc polymer [9-13]. Most of these PVAc copolymers are inexpensive, commercially available polymers with many desirable properties. However, there is an urgent need to find sustainable and bio-based monomers to be alternative sources that can be used in copolymerization with vinyl acetate.

Lignin is the third-largest natural macromolecular organic substance [14,15]. It has been classified as a byproduct of the paper industry-most of the generated lignin is burned or discharged, although it has excellent properties such as anti-ultraviolet and antimicrobial [16]. Many studies have shown that lignin can effectively filter ultraviolet (UV) light [17], whereas Tian et al. [18] reported that the addition of lignin nanoparticles into the PVA matrix leads to prepare a composite film with a shield of ultraviolet light (at least $70 \%$ ). It has been also used to enhance the physical and chemical properties of the PVAc polymer in several studies. For example, lignin was blended with PVAc to enhance or add new properties, such as UV resistance [6], to enhance the mechanical properties [19], and to improve the thermal stability of PVAc [20-22]. Consequently, the blending of PVAc with lignin at the molecular level through copolymerization leads to combine the properties of both, expanding the scope of application of PVAc in paper coating and also the utilization of lignin as biosource for coating materials [23-27]. On this approach, and based on our previous work, we found that the adding of lignin to PVAc via copolymerization showed a significant enhancement of the thermal stability of the PVAc [4], which seemed appropriate to be used for coating the paper due to its chemical structure, low cost, and moderate thermal stability.

In the present study, lignin-vinyl acetate copolymer containing different fractions of lignin was synthesized by copolymerization technique. The synthesized copolymer was successfully applied to coat the paper for enhancing its functional performance. The effects of the lignin-vinyl acetate copolymer on the physicochemical, air permeability, and mechanical properties of the coated paper were investigated. Our study was focused on the effect of lignin, which has a great impact on the application of the coating, water resistance, and air permeability properties and could afford new potential applications in paper packaging.

\section{Materials and Methods}

\subsection{Materials}

Sodium lignosulfonate was purchased from Shanghai Xushuo Biotechnology Co., Ltd. (Shanghai, China). Formaldehyde was supplied by Laiyang Kangde Chemical Co., Ltd. (Yantai, China). Acetone was purchase from Yantai Far East Fine Chemical Co., Ltd. (Yantai, China). Filter paper was provided from Fushun Civil Administration Filter Paper Co., Ltd. (Fushun, China). The vinyl chloroacetate (CVAc), vinyl acetate (VAc), diethylenetriamine (DETA), benzyl peroxide (BPO), polyvinyl alcohol (PVA) 1799 were provided from Shanghai McLean Biotechnology Co., Ltd. (Shanghai, China). Isopropanol was purchased from Tianjin Fuyu Fine Chemical Co., Ltd. (Tianjin, China).

\subsection{Methods}

\subsubsection{Polymer Synthesis}

PVAc and lignin-vinyl acetate copolymers were synthesized as described in our previous work [4]. In short, synthesis was done in two-steps; firstly, lignin-vinyl acetate (LVAc) monomer was prepared by simple grafting reaction of chlorovinyl acetate with animated lignin. Secondly, as-prepared LVAc and the acetate (VAc) monomers were polymerized in different ratios for the purpose of obtaining PVAc copolymer containing different fractions of lignin. The synthesized PVAc and its copolymers containing different fractions of lignin were separately dissolved in acetone (10 wt.\%) to prepare a coating solution in equal concentrations as shown in Figure 1. 


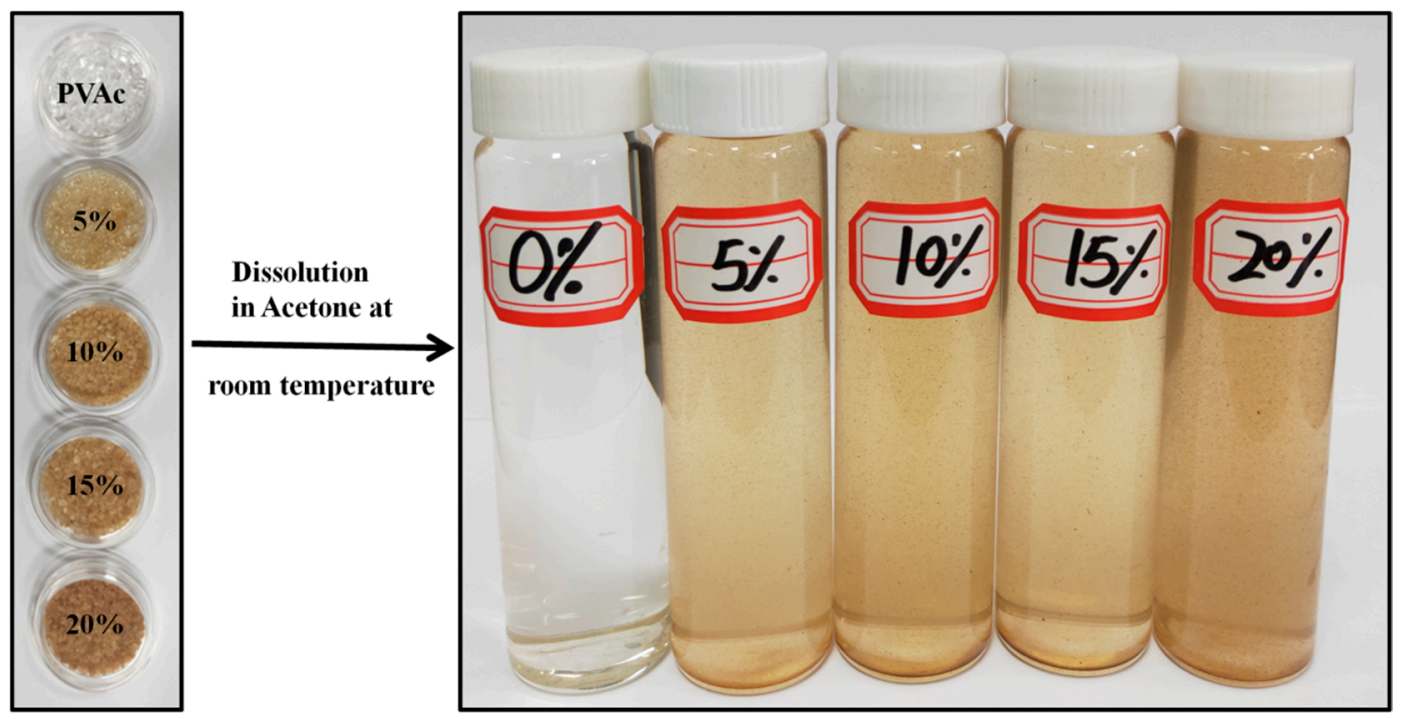

(a)

(b)

Figure 1. Pictures of (a) the prepared copolymers containing different fractions of lignin, and (b) the coating solutions of polyvinyl acetate (PVAc) and its copolymers.

\subsubsection{Paper Coating}

The dried filter paper was fixed tightly on the moveable holder which was moving at a constant speed $(10 \mathrm{~mm} / \mathrm{s})$. The coating process with PVAc and its lignin copolymers was achieved using a sprayer at a constant rate $(0.2 \mathrm{~mL} / \mathrm{min})$. The coating process was applied to one side of the paper, and the coating quantity was controlled to be $0.0067 \mathrm{~g} / \mathrm{cm}^{2}$. The coated papers were dried to remove acetone and then placed in standard conditions of room temperature and $50 \%$ humidity for one day using constant temperature and humidity test dryer model-DHS-010 (YASHILIN, Beijing, China).

\subsection{Characterization}

\subsubsection{Coating Weight}

The coating weight of the samples was measured by subtracting the weight of the papers before and after the coating process. The results were averaged from five replicates and presented as the average \pm the standard deviation.

\subsubsection{Thermogravimetric Analysis (TGA)}

Samples were tested with a TA thermogravimetric analyzer (TGA Q50, Woodland, CA, USA). The test for the samples was conducted under a nitrogen atmosphere (inert). The samples' weights were $5-15 \mathrm{mg}$ and the heating rate was adjusted at $15^{\circ} \mathrm{C} \cdot \mathrm{min}^{-1}$; the test temperatures were from 35 to $800{ }^{\circ} \mathrm{C}$ with the gas flow of $40 \mathrm{~mL} / \cdot$ min nitrogen.

\subsubsection{Differential Scanning Calorimetry (DSC)}

The samples were analyzed using a NETZSCH STA449 thermal analyzer (NETZSCHGerätebau $\mathrm{GmbH}$, Filderstadt, Germany). About $10 \mathrm{mg}$ of each sample was placed in a pan (aluminum-oxide) and heated from $-10{ }^{\circ} \mathrm{C}$ to $200{ }^{\circ} \mathrm{C}$ with a heating rate of $10^{\circ} \mathrm{C} \mathrm{min}-1$ under nitrogen atmospheres.

\subsubsection{Ultraviolet (UV) Spectrophotometry}

The dried paper was tested on a solid ultraviolet spectrophotometer (UV-2600, Shimadzu, Japan), with a wavelength range from 200 to $800 \mathrm{~nm}$. External dual detection was used to test the absorption wavelength. 


\subsubsection{Scanning Electron Microscopy (SEM)}

The paperboard specimens were cut into $5 \times 5 \mathrm{~mm}^{2}$ pieces for viewing the surface texture. The samples test was studied by field emission scanning electron microscope (FE-SEM, Regulus 8820, Tokyo, Japan).

\subsubsection{Air Permeability Test}

Coated papers were cut into a circular piece of paper with an area of $20 \mathrm{~cm}^{2}$, and a gas permeability tester (Deliang Testing Instrument Co., Ltd., Taipei, Taiwan, China) under a pressure of $2500 \mathrm{~Pa}$ measured the air permeability.

\subsubsection{Water Contact Angle}

The contact angle of water on the paper surface was measured with a contact angle analyzer (OCA50, Filderstadt, Germany) after a drop of distilled water about $5 \mu \mathrm{L}$ was placed on the surface of the coated or uncoated paper using a microsyringe. All paper samples $\left(4 \times 6 \mathrm{~cm}^{2}\right)$ were stuck on the movable sample stage leveled horizontally before the test.

\subsubsection{Fourier Transform Infrared Spectroscopy (FTIR)}

The coated paper was tested on Bruker's FTIR spectrometer (VERTEX70 FTIR, Karlsruhe, Germany). Each sample was scanned 32 times with a wavelength range of 400 to $4000 \mathrm{~cm}^{-1}$.

\subsubsection{Mechanical Properties}

Coated papers were cut into $63 \times 75 \mathrm{~mm}^{2}$ and tear index measured by a tear tester (SLY-1000, Labthink, Jinan, China). Then, the paper was cut into $15 \times 250 \mathrm{~mm}^{2}$ and the tensile index was measured by a tensile machine (XWL (B), Labthink). Coated paper with a diameter of more than $5 \mathrm{~cm}$ was then selected to test the burst index by burst resistance meter (BSM-1600B, Hangzhou Qingtong Brocade Automation Technology Co., Ltd., Hangzhou, China).

\subsubsection{Surface Free Energy Measurement Method}

The surface free energy (SFE) for coated papers was determined by measuring the contact angles $(\theta)$ between the solid surface (coated papers) and the test liquids, with known surface tensions (water), free surface energies of the coated papers were calculated using automatic Owens, Wendt, Rabel, and Kaelble (OWRK) calculation method [28,29]. The OWRK method is the most frequently used method for the determination of SFE $(\gamma)$ of polymer surfaces, along with their polar $\left(\gamma^{\mathrm{p}}\right)$ and dispersive $\left(\gamma^{\mathrm{d}}\right)$ part. The liquid was a droplet on the surface with a volume of $1 \mu \mathrm{L}$. The contact angles of the droplet were captured by a high-resolution charge-coupled device (CCD), camera, and measured after the initial contact of the droplet with the surface [30].

\section{Results and Discussion}

\subsection{Scanning Electron Microscope and Water Contact Angle Analysis}

To investigate and understand the morphology of the blank and coated paper, the samples were analyzed by the FE-SEM. Figure 2 shows the FE-SEM images of a blank and paper coated with PVAc and its copolymers with lignin. The FE-SEM image shows that uncoated paper has a porous and open network structure with a non-uniform surface due to fiber entanglement on the surface of the paper (Figure 2A). In contrast, as shown in Figure 2B-F, the fibers and pores holes were covered with the coating materials. Therefore, the paper surface became smoother, and less pore structure was observed with increasing the lignin content in the copolymer. Anyhow, there was some difference in the coated paper appearance attributed to the differences in the viscosity of the copolymers. Indeed, the good interpenetration and interaction between paper and copolymers, which is attributed 
to their chemical structure (composed of hydroxyl and acetate groups), leads to improve the mechanical and physical properties of coated paper.
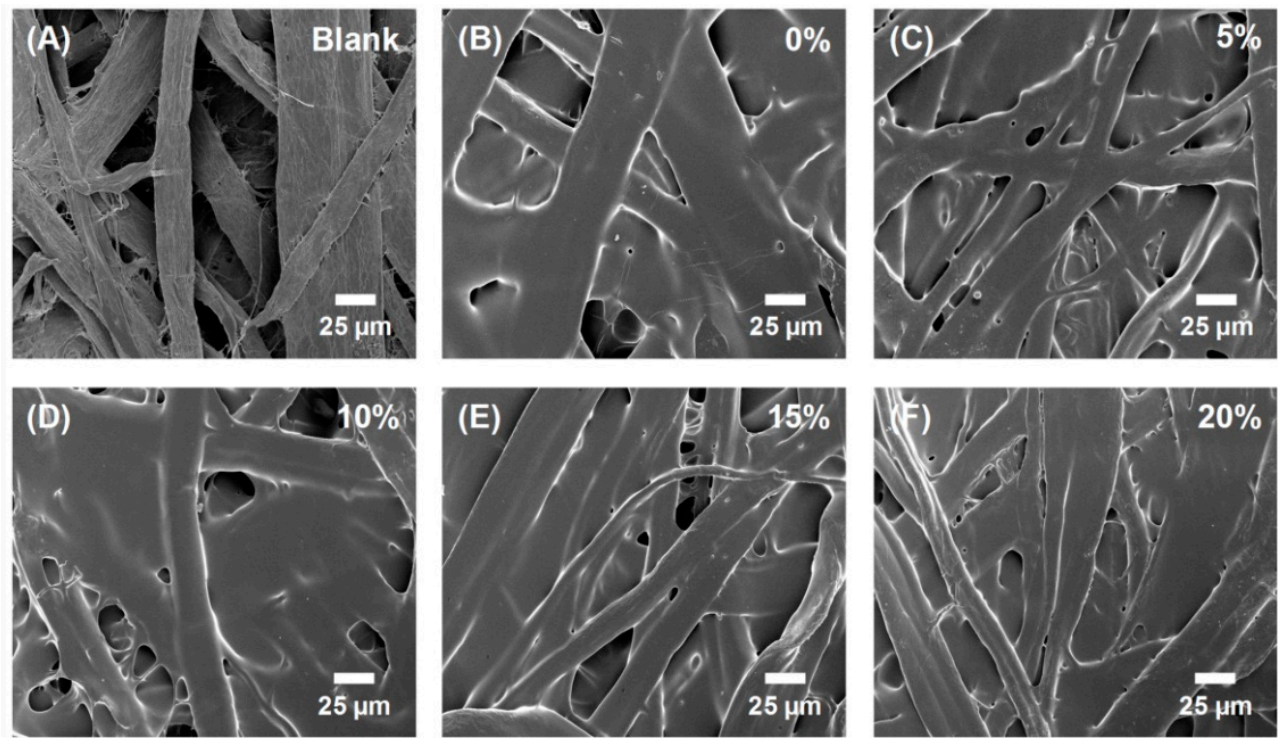

Figure 2. Electron micrographs of the surface of the blank paper (A) and paper coated with PVAc (B), and coated papers with copolymers containing different fractions of lignin (C-F).

To study the effect of copolymers on paper wettability, the contact angle test was performed and the obtained results are shown in Figure 3. It was observed that the contact angles were increased from $2.1^{\circ}$ for the blank paper to nearly $90^{\circ}$ after coating. The coating with a copolymer containing $10 \%$ lignin showed the highest water-resistance with a water contact angle of $90^{\circ}$. The result showed that the copolymer can enhance the water-resistance of the paper, which is due to fact that lignin itself has a hydrophobic nature, although it is composed of multi hydrophilic groups.

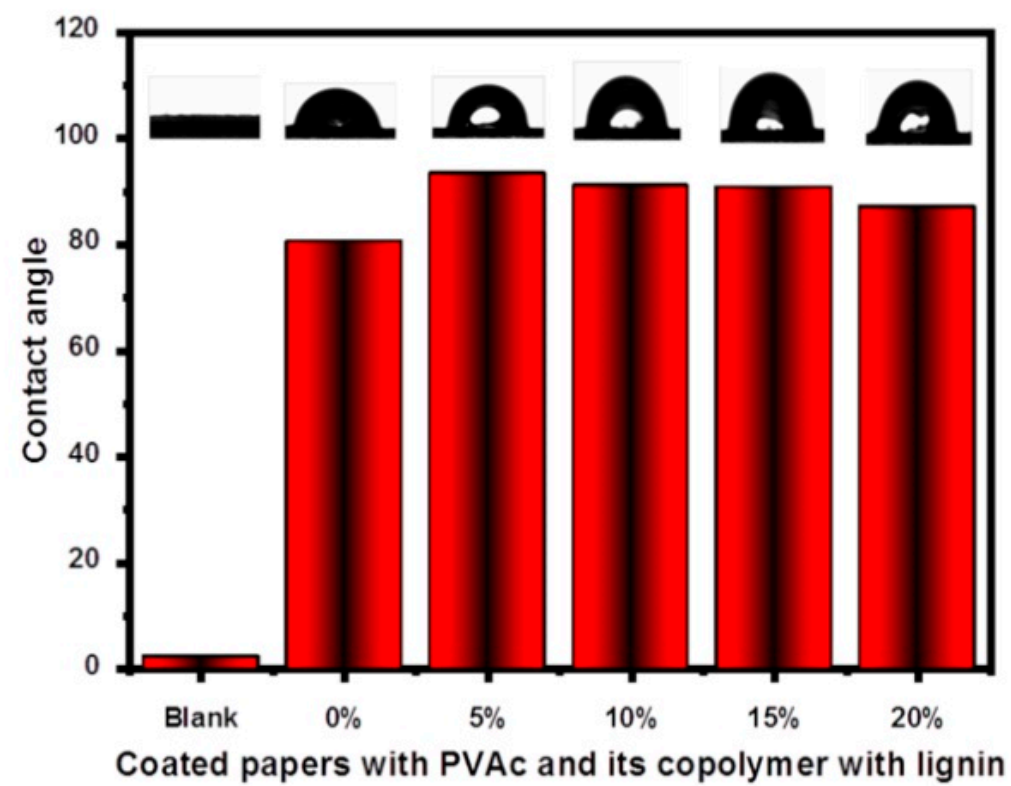

Figure 3. The water contact angle of the blank paper and coated papers with PVAc and its copolymers containing different lignin fractions.

The values of the measured tensile index tear index and bursting resistance of the blank paper and coated paper shown in Table 1 and Figure 4. As shown in Table 1, the 
tensile index and burst resistance have been significantly increased with the increase of the lignin content in the coated material, which may be because lignin-based copolymers can fill in between the fibers and enhance the adhesion of the fiber, thus hindering their sliding and stretching. From Figure 4, one can observe that the tensile index of coated papers increased significantly when the lignin fraction increased from $0 \%$ to $10 \%$ and then decreased slightly with the increase of lignin fraction in the copolymer. Because lignin molecules have a rigid structure, the coated paper with a copolymer containing a small fraction of lignin exhibited a good enhancement in the tensile index. These results agree with those reported in the literature [31-33].

Table 1. The values of ration, tearing, tensile, and bursting tests of the blank paper and paper coated with PVAc and its copolymers containing different fractions of lignin.

\begin{tabular}{|c|c|c|c|c|c|c|}
\hline Test & Blank & $0 \%$ & $5 \%$ & $10 \%$ & $15 \%$ & $20 \%$ \\
\hline $\begin{array}{l}\text { Ration } \\
\left(\mathrm{g} / \mathrm{m}^{2}\right)\end{array}$ & 86.435 & 108.330 & 105.119 & 111.158 & 109.837 & 103.043 \\
\hline $\begin{array}{c}\text { Tear } \\
\left(\mathrm{mN} \cdot \mathrm{m}^{2} / \mathrm{g}\right)\end{array}$ & 11.666 & 7.821 & 7.759 & 7.956 & 7.403 & 7.214 \\
\hline $\begin{array}{l}\text { Tensile } \\
\text { (N.m/g) }\end{array}$ & 43.848 & 72.740 & 73.187 & 81.596 & 64.368 & 61.528 \\
\hline $\begin{array}{l}\text { Bursting } \\
\left(\mathrm{kPa} \cdot \mathrm{m}^{2} / \mathrm{g}\right)\end{array}$ & 2.742 & 5.040 & 5.280 & 5.285 & 4.575 & 5.192 \\
\hline
\end{tabular}

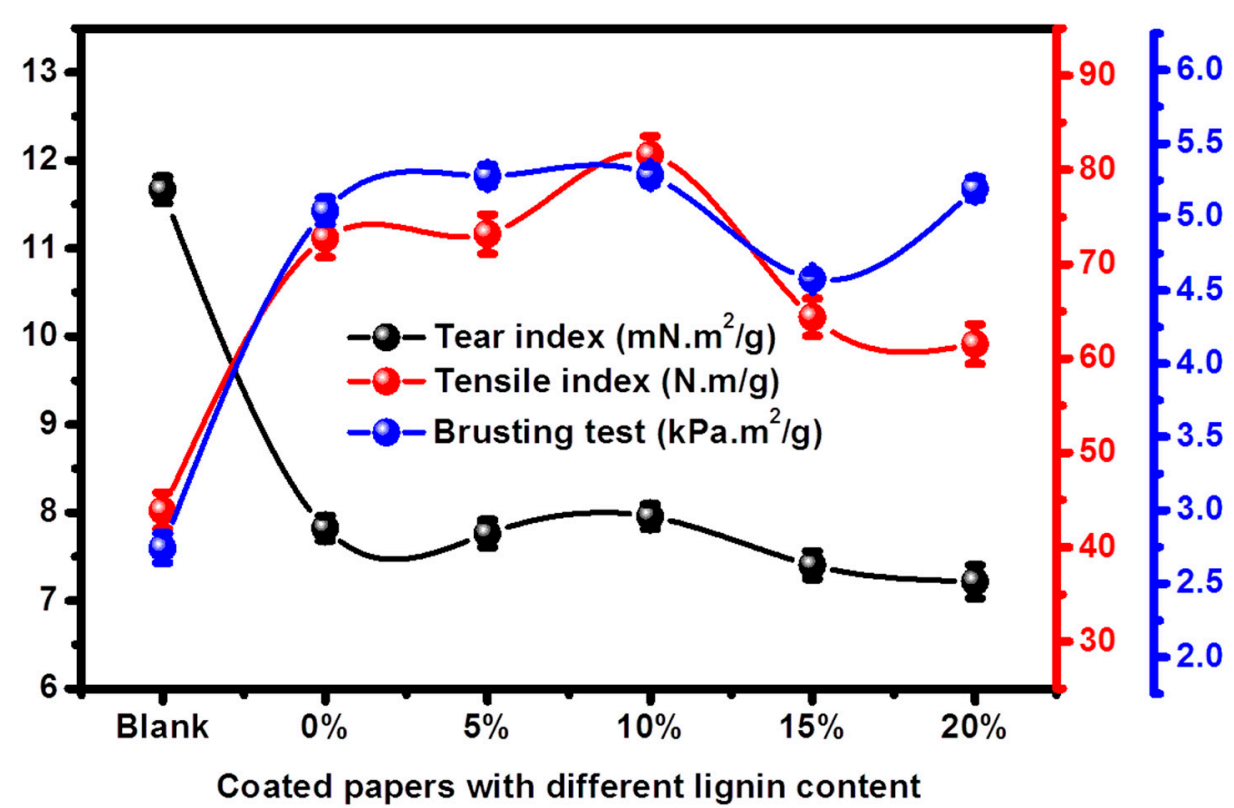

Figure 4. The physical properties of the blank paper and the papers coated with PVAc and its copolymers containing different fractions of lignin.

On the contrary, the tearing index test of the coated papers showed a notable decrease. This is due to lignin having a rigid structure which forms a rigid film-like structure on the paper surface and makes the coated paper more brittle and reduces its tearing index.

\subsection{UV and FTIR Spectroscopy Analysis}

UV spectroscopy also was applied to monitoring the effect of PVAc and its lignin copolymers on the light properties of coated papers. Compared to the UV spectrum of the blank pape, the spectra of the coated papers are exhibited strong absorption peaks at 235 and $275 \mathrm{~nm}$ (Figure 5a) which associated with the phenolic structure of lignin (i.e., lignin 
has a UV band that appears at 200-230 nm and 260-280 nm) [34]. It is worth mentioning that the UV absorption of coated papers seemed to be associated with the fraction of lignin in the copolymers. Due to the strength of the UV absorption, the transmittance values of the UV light $(<400 \mathrm{~nm}$ ) were neglected for the coated papers (Figure 5a), which indicates that the copolymers have similar properties to those polymers which are classified as UV-blockers. This finding is consistent with the literature reported by Parit et al. [35].
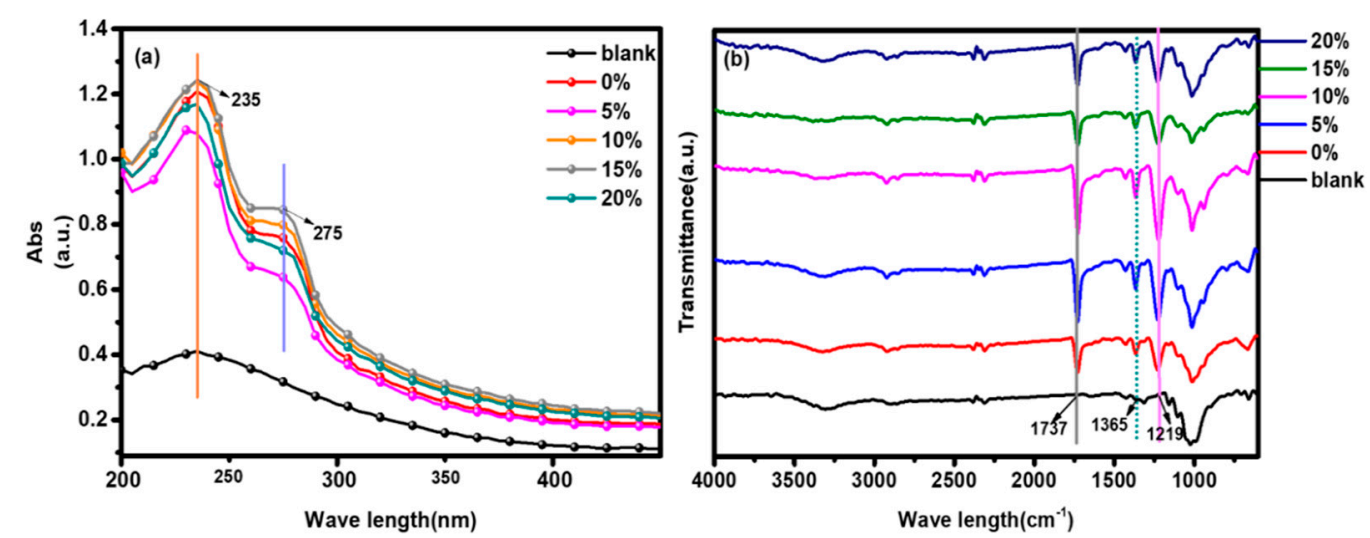

Figure 5. Ultraviolet (UV) and FTIR of the blank paper and paper coated with PVAc and its lignin copolymers containing different fractions of lignin, (a): UV absorption (b): FTIR absorption.

FTIR spectra of the blank and coated papers with PVAc and the copolymer are shown in Figure $5 b$. As seen, the blank paper has obvious intensity peaks of $\mathrm{O}-\mathrm{H}$ vibration at $3319 \mathrm{~cm}^{-1}$ due to cellulose contains a large amount of $-\mathrm{OH}$ groups. Subsequently, after coating with copolymers, this peak weakened but still existed, indicating the interaction between paper and copolymers was achieved. Besides, the spectra of coated papers exhibited three new peaks at 1219,1365 , and $1737 \mathrm{~cm}^{-1}$ which are associated with $\mathrm{CH}_{2}$ stretching, stretching of $\mathrm{C}-\mathrm{OH}$, the vibration of carbonyl $-\mathrm{C}=\mathrm{O}$, and stretching vibration of $\mathrm{C}-\mathrm{O}-\mathrm{C}$, respectively [36]. These results are indicating the presence of vinyl acetate on coated paper, and consistent with the literature [36,37].

\subsection{Air Permeability Analysis and Thermal Stability Analysis}

As expected, the coating with copolymer decreased air permeability. Figure 6 shows that the air permeability of the blank paper is $104.75 \mathrm{~mm} / \mathrm{s}$. Subsequently, after coating with copolymers, the air permeability was decreased significantly to the lowest level $(30.275 \mathrm{~mm} / \mathrm{s})$ with $0 \%$ content of lignin in the copolymer. This is because the lignin-based copolymer could fill the gap between fibers, binding the fibers, reducing the porosity, and increasing the tightness, thereby reducing the air permeability. It is worth mentioning that lignin content in the copolymers affects the air permeability and it could be used to control the air resistance of paper. These results are consistent with SEM results and agree with the data reported in the literature [38,39].

The thermogravimetric analysis (TGA) and derivative thermogravimetric analysis (DTGA) of the blank paper and paper coated with PVAc and its lignin copolymers containing different lignin fractions were carried out to investigate the effects of coating on the thermal properties of coated papers. As shown in the TGA curves (Figure 7a), all samples show three stages of loss in weight. In the first stage, a common behavior observed for all samples is the dehydration process, in which $8-12 \mathrm{wt}$. \% of water was removed in the temperature range between 35 and $130{ }^{\circ} \mathrm{C}$. The loss of mass in this stage depends on the initial moisture content of the samples. It was observed that there was a slight decrease in the amount of loss in weight after coating the papers. Besides, the blank paper has shown an ability to absorb more water than coated paper, possibly due to it having a more porous structure, as was seen in the SEM photographs. The DTGA curves, Figure 7b showed that the main thermal decomposition (in the second stage) of the blank paper happened very 
fast and in the range of temperature between $290-410{ }^{\circ} \mathrm{C}$ and with a maximum degradation rate of $391^{\circ} \mathrm{C}$ [40]. While the DTGA of papers coated with copolymer depicted a wide range of thermal decomposition $\left(240-420^{\circ} \mathrm{C}\right)$ and their maximum degradation temperature slightly decreased. This is due to the thermal degradation of vinyl acetate in PVAc and co-polymers takes place early [5]. Also, the presence of lignin molecules in copolymers creates a new inter-chain interaction with neighbor PVAc molecules (cross-linking) which restricts the motion of the main-chain $[5,6]$. Notably, the decomposition in this stage is due to the thermal-cracking reaction of $\mathrm{C}-\mathrm{C}$ and $\mathrm{C}-\mathrm{O}-\mathrm{C}$ bonds (chain scission). The last phase of thermal decomposition happened at a temperature range of 420 to $600{ }^{\circ} \mathrm{C}$; unlike the blank paper, the coated papers showed a higher loss in weight. The decomposition is due to the carbonization and evaporation of some volatile compounds $\left(\mathrm{CO}\right.$ and $\left.\mathrm{CO}_{2}\right)$ [41]. At the end of thermal degradation, the ash (carbon) content of the coated papers was higher than that of the blank paper.

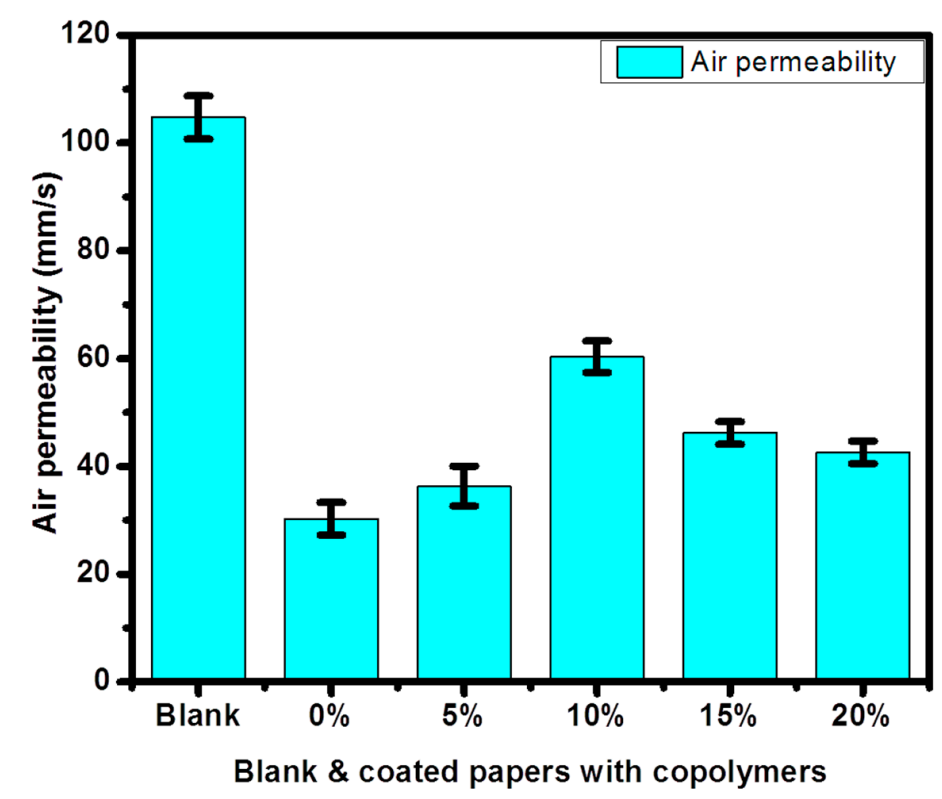

Figure 6. The air permeability of the blank paper and paper coated with PVAc and its copolymers containing different fractions of lignin.
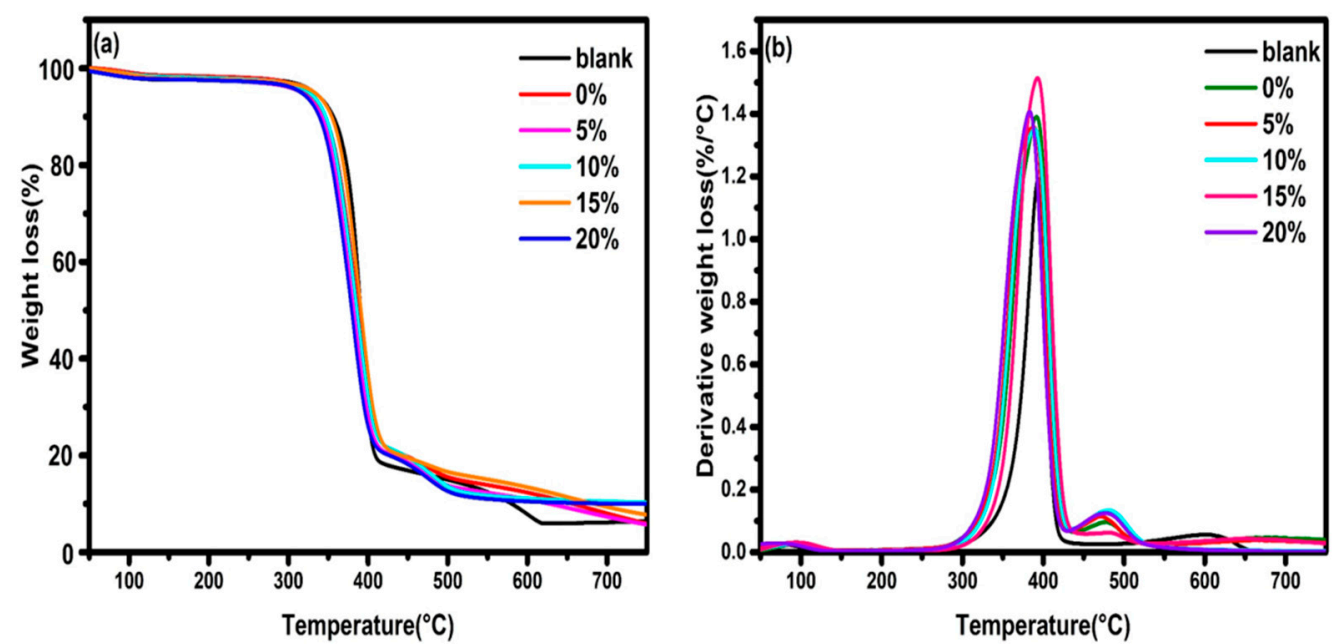

Figure 7. The thermogravimetric analysis (TGA) scans (a), and the derivative thermogravimetric analysis (DTGA) curve (b) of the blank paper and papers coated with PVAc and its lignin copolymers containing different fractions of lignin. 
Figure 8 shows the differential scanning calorimetry (DSC) curves of paper coated with PVAc and its copolymer containing different fractions of lignin; all samples of coated papers displayed a well-defined glass transition $\left(\mathrm{T}_{\mathrm{g}}\right)$. The paper coated with PVAc showed a sharp $\mathrm{T}_{\mathrm{g}}$ at $43{ }^{\circ} \mathrm{C}$, while all the papers coated with copolymers showed an obvious increase in their $\mathrm{T}_{\mathrm{g}} \mathrm{s}$ which reached $56{ }^{\circ} \mathrm{C}$ when the fraction of lignin in the copolymer was $20 \%$. Besides, the $\mathrm{T}_{\mathrm{g}}$ s peaks became broader thanks to the introduction of the phase change component of lignin molecules. These changes referred to the segment motion of the copolymer chains restricted as a result of the interaction between the copolymer and the surface of the paper [42]. The increases of $\mathrm{T}_{\mathrm{g}} \mathrm{s}$ of paper coated with the copolymer are attributed to the changes in the structure and crystallization behavior of the PVAc with the introduction of lignin molecules in its copolymers, as similarly reported by Nana Zhang [4]. Notably, the increase of $\mathrm{T}_{\mathrm{g}}$ values was directly proportional to the amount of lignin fractions in the copolymers; this is due to the lignin's molecules are acting as a crosslinker between the neighboring molecules of the copolymers that leads to hindering their motion under heating, which implies enhancing the thermal stability as was suggested by Yao et. al [43] and Wang et.al [44]. Moreover, the DSC results are in good agreement with those obtained by thermogravimetric analysis (TGA) and the previous literature $[5,6]$. Thus, the fractions of lignin on the copolymer arguably have a significant impact on the thermal properties of PVAc, which leads to increases in the range of enthalpy relaxation and $\mathrm{T}_{\mathrm{g}} \mathrm{s}$.

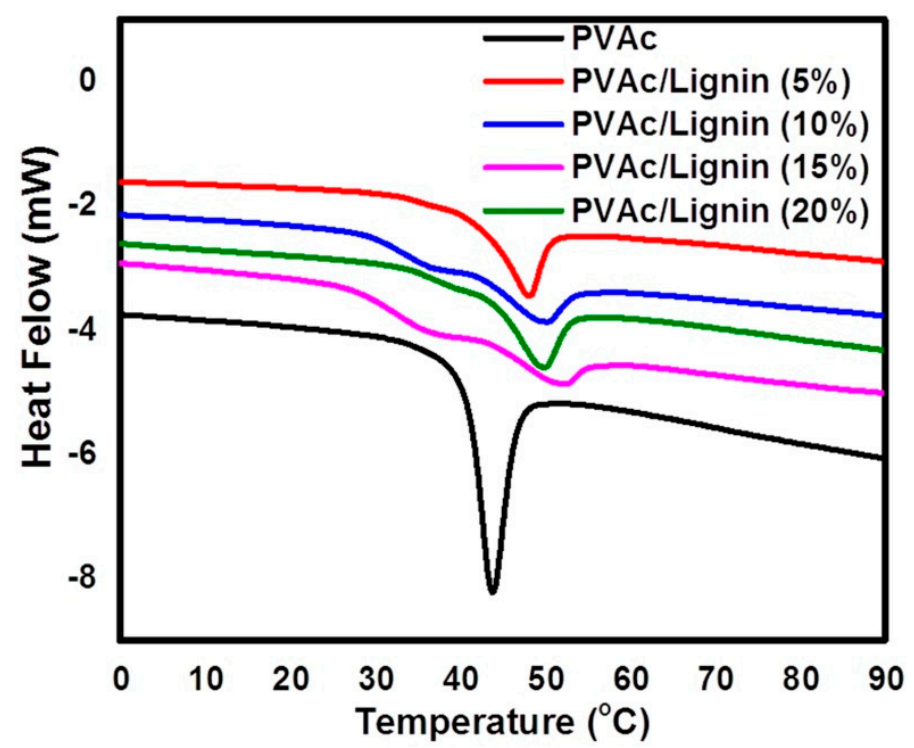

Figure 8. Differential scanning calorimetry (DSC) of papers coated with PVAc and its lignin copolymers containing different fractions of lignin.

\subsection{Surface Free Energy (SFE)}

The SFE of papers and paper-coated with copolymers samples in polar dispersive components were done based on the measured surface contact angle $\theta$ of the layer, the known free energy of the surface and the liquid was used to calculate the $\gamma_{S}^{P}$ and $\gamma_{S}^{D}$ by formal Equation (1), and the obtained results are shown in Table 2.

$$
\gamma_{L}(1+\cos \theta)=2\left(\sqrt{\gamma_{S}^{D}} \times \sqrt{\gamma_{L}^{D}}+\sqrt{\gamma_{S}^{P}} \times \sqrt{\gamma_{L}^{P}}\right)
$$


Table 2. Surface free energy and values of dispersion force of the blank paper and coated paper with PVAc and its copolymers containing different fractions of lignin.

\begin{tabular}{|c|c|c|c|c|c|c|}
\hline \multirow{2}{*}{$\begin{array}{c}\text { Coated } \\
\text { Paper }\end{array}$} & \multicolumn{2}{|c|}{ Contact Angle } & \multirow{2}{*}{$\mathrm{\gamma}_{\mathrm{S}}^{\mathrm{P}} / \mathrm{mJ} \cdot \mathrm{m}^{-2}$} & \multirow{2}{*}{$\mathrm{\gamma}_{\mathrm{S}}^{\mathrm{D}} / \mathrm{mJ} \cdot \mathrm{m}^{-2}$} & \multirow{2}{*}{$\mathrm{\gamma}_{\mathrm{s}} / \mathrm{mJ} \cdot \mathrm{m}^{-2}$} & \multirow{2}{*}{$\mathrm{\gamma}_{\mathrm{s}}^{\mathrm{P}} / \mathrm{\gamma}_{\mathrm{s}}^{\mathrm{D}}$} \\
\hline & $\theta_{1}$ & $\theta_{2}$ & & & & \\
\hline $0 \%$ & 14.2 & 86.4 & 3.83 & 28.02 & 31.85 & 0.1365 \\
\hline $5 \%$ & 23.1 & 85 & 5.19 & 26.63 & 31.82 & 0.1948 \\
\hline $10 \%$ & 23.2 & 92.8 & 2.18 & 26.61 & 28.79 & 0.0818 \\
\hline $15 \%$ & 15.7 & 80.0 & 6.41 & 27.83 & 34.25 & 0.2305 \\
\hline $20 \%$ & 14.4 & 107.4 & 0.01 & 28.00 & 28.01 & 0.0005 \\
\hline
\end{tabular}

Note: $\theta_{1}, \theta_{2}$ are the contact angles of benzene and water of coated paper, respectively.

As can be seen from Table 2, the surface free energy of the coatings with a lignin content of $10 \%$ and $20 \%$ was reduced by $9.6 \%$ and $12.1 \%$. Compared to the paper coated with $0 \%$ of lignin, the $\gamma_{S}^{\mathrm{P}} / \gamma_{S}^{\mathrm{D}}$ significantly reduced $[45,46]$. This indicates that the addition of a fraction of lignin reduces the surface free energy, and inhibits the diffusion of droplets on the surface which leads to improving the liquid-repellent performance of coated paper [47]. The dispersion force of the coating does not change much, because the dispersion forces on the solid surface are formed by the van der Waals force between the molecules [48]. The polar force of the surface free energy of the paper coated with copolymer decreased by $99.7 \%$, because of the hydrophobic nature of lignin, which acted to form a hydrophobic layer on the surface after coating that reduced the surface free energy of the coated paper [49]. As a result, the water-resistance of the coated paper was enhanced significantly.

\section{Conclusions}

In summary, lignin-vinyl acetate copolymers with varying amounts of lignin of $0 \%, 5 \%$, $10 \%, 15 \%$, and $20 \%$ were successfully used for coating paper. The effect of lignin content of the copolymer on physical and mechanical properties was evaluated with different techniques. SEM micrographs showed that paper surface porosity decreased significantly when the paper was coated with copolymers; this is due to good interaction between copolymers and paper surface and to forming a continuous and smooth coating layer. Coating with copolymers enhanced the surface smoothness and increased the waterproof, air resistance, bursting, stiffness, and tensile strength of coated papers. Interestingly, paper coated with copolymers was shown to respond to UV absorption. Accordingly, it can be concluded that the application of lignin-vinyl acetate copolymer as a coating material for the paper provides a more homogeneous, smooth, and stable layer on its surface, which leads to adding multiple desirable properties to the paper and makes it more efficient in use.

Author Contributions: Conceptualization, S.W. and F.K.; methodology, N.Z.; validation, Y.Y.; investigation, P.L. and M.E.G.; writing —original draft, N.Z.; writing—review and editing, M.E.G.; supervision, S.W.; project administration, F.K. All authors have read and agreed to the published version of the manuscript.

Funding: This research was funded by the National Key R\&D Program of China (No. 2017YFB0308000) and the National Natural Science Foundation of China (Grant No.31971605. 31570566. 31600472).

Institutional Review Board Statement: Not applicable.

Informed Consent Statement: Not applicable.

Data Availability Statement: Data available on request.

Conflicts of Interest: The authors declare no conflict of interest. 


\section{References}

1. Rastogi, V.K.; Samyn, P. Bio-based coatings for paper applications. Coatings 2015, 5, 887-930. [CrossRef]

2. Khwaldia, K.; Arab-Tehrany, E.; Desobry, S. Biopolymer coatings on paper packaging materials. Compr. Rev. Food Sci. Food Saf. 2010, 9, 82-91. [CrossRef]

3. Sahin, H.T.; Arslan, M.B. A study on physical and chemical properties of cellulose paper immersed in various solvent mixtures. Int. J. Mol. Sci. 2008, 9, 78-88. [CrossRef]

4. Zhang, N.; Wang, S.; Gibril, M.E.; Kong, F. The copolymer of polyvinyl acetate containing lignin-vinyl acetate monomer: Synthesis and characterization. Eur. Polym. J. 2020, 123, 109411. [CrossRef]

5. Panesar, S.S.; Jacob, S.; Misra, M.; Mohanty, A.K. Functionalization of lignin: Fundamental studies on aqueous graft copolymerization with vinyl acetate. Ind. Crop. Prod. 2013, 46, 191-196. [CrossRef]

6. Silva, M.F.; Pineda, E.A.G.; Hechenleitner, A.A.W.; Fernandes, D.M.; Lima, M.K.; Bittencourt, P.R.S. Characterization of poly(vinyl acetate)/sugar cane bagasse lignin blends and their photochemical degradation. J. Therm. Anal. Calorim. 2011, 106, 407-413. [CrossRef]

7. Petković, G.; Vukoje, M.; Bota, J.; Pasanec Preprotić, S. Enhancement of polyvinyl acetate (PVAc) adhesion performance by $\mathrm{SiO}_{2}$ and $\mathrm{TiO}_{2}$ nanoparticles. Coatings 2019, 9, 707. [CrossRef]

8. Kaboorani, A.; Riedl, B. Improving performance of polyvinyl acetate (PVA) as a binder for wood by combination with melamine based adhesives. Int. J. Adhes. Adhes. 2011, 31, 605-611. [CrossRef]

9. Dossi, M.; Liang, K.; Hutchinson, R.A.; Moscatelli, D. Investigation of free-radical copolymerization propagation kinetics of vinyl acetate and methyl methacrylate. J. Phys. Chem. B 2010, 114, 4213-4222. [CrossRef]

10. Zhang, Y.; Pan, S.; Ai, S.; Liu, H.; Wang, H.; He, P. Semi-continuous emulsion copolymerization of vinyl acetate and butyl acrylate in presence of AMPS. Iran. Polym. J. 2014, 23, 103-109. [CrossRef]

11. Zhang, Y.; Pang, B.; Yang, S.; Fang, W.; Yang, S.; Yuan, T.Q.; Sun, R.C. Improvement in wood bonding strength of poly (vinyl acetate-butyl acrylate) emulsion by controlling the amount of redox initiator. Materials 2018, 11, 89. [CrossRef] [PubMed]

12. Wenjuan, L.; Xiao, Y.; Zhan, W.; Jing, Z.; Jingdi, C. The preparation and performance characteristics of polyvinyl chloride-co-vinyl acetate modified membranes. Energy Procedia 2011, 5, 1158-1162. [CrossRef]

13. Rosdi, M.R.H.; Ariffin, A. evaluation of flow ability response in EVA emulsion preparation with different vinyl acetate percentage by intrinsic viscosity measurement. Procedia Chem. 2016, 19, 455-461. [CrossRef]

14. Spasojevic, D.; Zmejkoski, D.; Glamoclija, J.; Nikolic, M.; Sokovic, M.; Milosevic, V.; Jaric, I.; Stojanovic, M.; Marinkovic, E.; Barisani-Asenbauer, T.; et al. Lignin model compound in alginate hydrogel: A strong antimicrobial agent with high potential in wound treatment. Int. J. Antimicrob. Agents 2016, 48, 732-735. [CrossRef] [PubMed]

15. Suhas; Carrott, P.J.; Ribeiro Carrott, M.M. Lignin—from natural adsorbent to activated carbon: A review. Bioresour Technol 2007, 98, 2301-2312. [CrossRef] [PubMed]

16. Ivanov, A.E.; Halthur, T.; Ljunggren, L. Flow permeable composites of lignin and poly(vinyl alcohol): Towards removal of bisphenol A and erythromycin from water. J. Environ. Chem. Eng. 2016, 4, 1432-1441. [CrossRef]

17. Nichols, J.A.; Katiyar, S.K. Skin photoprotection by natural polyphenols: Anti-inflammatory, antioxidant and DNA repair mechanisms. Arch. Dermatol. Res. 2010, 302, 71-83. [CrossRef] [PubMed]

18. Tian, D.; Hu, J.; Bao, J.; Chandra, R.P.; Saddler, J.N.; Lu, C. Lignin valorization: Lignin nanoparticles as high-value bio-additive for multifunctional nanocomposites. Biotechnol. Biofuels 2017, 10, 192. [CrossRef] [PubMed]

19. Li, Y.; Mlynár, J.; Sarkanen, S. The first 85\% kraft lignin-based thermoplastics. J. Polym. Sci. Part B Polym. Phys. 1997, 35, 1899-1910. [CrossRef]

20. Li, Y.; Sarkanen, S. Miscible blends of kraft lignin derivatives with low-tg polymers. Macromolecules 2005, 38, 2296-2306. [CrossRef]

21. Gregorová, A.; Košíková, B.; Moravčík, R. Stabilization effect of lignin in natural rubber. Polym. Degrad. Stab. 2006, 91, 229-233. [CrossRef]

22. Mohsen-Nia, M.; Mohammad Doulabi, F.S. Synthesis and characterization of polyvinyl acetate/montmorillonite nanocomposite by in situ emulsion polymerization technique. Polym. Bull. 2011, 66, 1255-1265. [CrossRef]

23. Xing, Q.; Ruch, D.; Dubois, P.; Wu, L.; Wang, W.-J. Biodegradable and high-performance poly(butylene adipate-co-terephthalate)lignin UV-blocking films. Acs Sustain. Chem. Eng. 2017, 5, 10342-10351. [CrossRef]

24. Sadeghifar, H.; Venditti, R.; Jur, J.; Gorga, R.E.; Pawlak, J.J. Cellulose-lignin biodegradable and flexible UV protection film. Acs Sustain. Chem. Eng. 2016, 5, 625-631. [CrossRef]

25. Xiong, F.; Wu, Y.; Li, G.; Han, Y.; Chu, F. Transparent nanocomposite films of lignin nanospheres and poly(vinyl alcohol) for UV-absorbing. Ind. Eng. Chem. Res. 2018, 57, 1207-1212. [CrossRef]

26. Avelino, F.; de Oliveira, D.R.; Mazzetto, S.E.; Lomonaco, D. Poly(methyl methacrylate) films reinforced with coconut shell lignin fractions to enhance their UV-blocking, antioxidant and thermo-mechanical properties. Int. J. Biol. Macromol. 2019, 125, 171-180. [CrossRef] [PubMed]

27. Wang, C.; Venditti, R.A. UV Cross-linkable lignin thermoplastic graft copolymers. Acs Sustain. Chem. Eng. 2015, 3, 1839-1845. [CrossRef]

28. Huang, P.K.; Wu, F.; Shen, B.; Zheng, H.; Ren, Q.; Luo, H.B.; Zheng, W.G. Biomimetic porous polypropylene foams with special wettability properties. Compos. Part B-Eng. 2020, 190. [CrossRef] 
29. Zhang, Z.Y.; Wang, W.L.; Korpacz, A.N.; Dufour, C.R.; Weiland, Z.J.; Lambert, C.R.; Timko, M.T. Binary liquid mixture contactangle measurements for precise estimation of surface free energy. Langmuir 2019, 35, 12317-12325. [CrossRef] [PubMed]

30. Rudawska, A.; Jacniacka, E. Analysis for determining surface free energy uncertainty by the Owen-Wendt method. Int. J. Adhes. Adhes. 2009, 29, 451-457. [CrossRef]

31. Salvini, A.; Saija, L.M.; Finocchiaro, S.; Gianni, G.; Giannelli, C.; Tondi, G. A new methodology in the study of PVAc-based adhesive formulations. J. Appl. Polym. Sci. 2009, 114, 3841-3854. [CrossRef]

32. Chapter 7-Lignin-Modified Materials and Their Applications. In Lignin Chemistry and Applications; Huang, J.; Fu, S.; Gan, L. (Eds.) Elsevier: Amsterdam, The Netherlands, 2019; pp. 181-210. [CrossRef]

33. Yang, W.; Qi, G.; Kenny, J.M.; Puglia, D.; Ma, P. Effect of cellulose nanocrystals and lignin nanoparticles on mechanical, antioxidant and water vapour barrier properties of glutaraldehyde crosslinked PVA films. Polymers 2020, 12, 1364. [CrossRef] [PubMed]

34. Sirviö, J.A.; Ismail, M.Y.; Zhang, K.; Tejesvi, M.V.; Ämmälä, A. Transparent lignin-containing wood nanofiber films with UV-blocking, oxygen barrier, and anti-microbial properties. J. Mater. Chem. A 2020, 8, 7935-7946. [CrossRef]

35. Parit, M.; Saha, P.; Davis, V.A.; Jiang, Z. Transparent and homogenous cellulose nanocrystal/lignin UV-protection films. Acs Omega 2018, 3, 10679-10691. [CrossRef]

36. Tambe, S.P.; Singh, S.K.; Patri, M.; Kumar, D. Ethylene vinyl acetate and ethylene vinyl alcohol copolymer for thermal spray coating application. Prog. Org. Coat. 2008, 62, 382-386. [CrossRef]

37. Vahabi, H.; Gholami, F.; Karaseva, V.; Laoutid, F.; Mangin, R.; Sonnier, R.; Saeb, M.R. Novel nanocomposites based on poly(ethylene- co -vinyl acetate) for coating applications: The complementary actions of hydroxyapatite, MWCNTs and ammonium polyphosphate on flame retardancy. Prog. Org. Coat. 2017, 113, 207-217. [CrossRef]

38. Hult, E.-L.; Ropponen, J.; Poppius-Levlin, K.; Ohra-Aho, T.; Tamminen, T. Enhancing the barrier properties of paper board by a novel lignin coating. Ind. Crop. Prod. 2013, 50, 694-700. [CrossRef]

39. Wang, W.; Guo, T.; Sun, K.; Jin, Y.; Gu, F.; Xiao, H. Lignin redistribution for enhancing barrier properties of cellulose-based materials. Polymers 2019, 11, 1929. [CrossRef]

40. Mousavioun, P.; Halley, P.J.; Doherty, W.O.S. Thermophysical properties and rheology of PHB/lignin blends. Ind. Crop. Prod. 2013, 50, 270-275. [CrossRef]

41. Chelazzi, D.; Chevalier, A.; Pizzorusso, G.; Giorgi, R.; Menu, M.; Baglioni, P. Characterization and degradation of poly(vinyl acetate)-based adhesives for canvas paintings. Polym. Degrad. Stab. 2014, 107, 314-320. [CrossRef]

42. Mao, Y.; Gong, J.; Zhu, M.; Ito, H. Crystal transition behavior and thermal properties of thermal-energy-storage copolymer materials with an n-behenyl side-chain. Polymers 2019, 11, 1512. [CrossRef]

43. Yao, D.; Qu, B.; Wu, Q. Photoinitiated crosslinking of ethylene-vinyl acetate copolymers and characterization of related properties. Polym. Eng. Sci. 2007, 47, 1761-1767. [CrossRef]

44. Wang, K.; Deng, Q. The thermal and mechanical properties of poly(ethylene-co-vinyl acetate) random copolymers (PEVA) and its covalently crosslinked analogues (cPEVA). Polymers 2019, 11, 1055. [CrossRef]

45. Tavana, H.; Lam, C.N.; Grundke, K.; Friedel, P.; Kwok, D.Y.; Hair, M.L.; Neumann, A.W. Contact angle measurements with liquids consisting of bulky molecules. J. Colloid Interface Sci. 2004, 279, 493-502. [CrossRef] [PubMed]

46. Schuman, T.; Wikström, M.; Rigdahl, M. Coating of surface-modified papers with poly(vinyl alcohol). Surf. Coat. Technol. 2004, 183, 96-105. [CrossRef]

47. Notley, S.M.; Norgren, M. Surface energy and wettability of spin-coated thin films of lignin isolated from wood. Langmuir 2010, 26, 5484-5490. [CrossRef] [PubMed]

48. Kakar, M.R.; Hamzah, M.O.; Akhtar, M.N.; Woodward, D. Surface free energy and moisture susceptibility evaluation of asphalt binders modified with surfactant-based chemical additive. J. Clean. Prod. 2016, 112, 2342-2353. [CrossRef]

49. Chibowski, E.; Terpilowski, K. Surface free energy of sulfur-revisited I. Yellow and orange samples solidified against glass surface. J. Colloid Interface Sci. 2008, 319, 505-513. [CrossRef] 